\begin{tabular}{|c|l|}
\hline Title & Differentiated egg size of the cannibalistic sal amander Hynobius retardatus \\
\hline Author(s) & Michimae, Hirofumi \\
\hline Citation & Journal of Ethology, 25(2), 153-158 \\
\hline htps://doi.org/L0.1007/310164006-0009-9 \\
\hline Issue Date & 2007-05 \\
\hline Doc URL & http://hdl.handle.net/2115/25158 \\
\hline Rights & The original publication is available at www.springerlink.com \\
\hline Type & article (author version) \\
\hline File Information & JE25-2.pdf \\
\hline
\end{tabular}

Instructions for use 


\title{
Differentiated egg size of the cannibalistic salamander Hynobius retardatus
}

\author{
Hirofumi MICHIMAE
}

Division of Life System Sciences, Faculty of Advanced Life Science, Hokkaido University, Sapporo 060-0810, Japan

(with 15 pages of text, 3 tables, 3 figures and 1 page of figure legends)

Correspondence: H. Michimae

e-mail: hirofumi@sci.hokudai.ac.jp

Phone and fax: $+81-11-7064455$ 
Abstract Larvae of the salamander, Hynobius retardatus, are carnivorous, and even though there are two morphs, a typical morph and a broad-headed or "cannibal" morph, both of them are cannibalistic. They also sometimes eat other large prey, for example larvae of the frog, Rana pirica. In natural habitats, the use of both conspecific and R. pirica larvae as food may contribute more strongly to high survival and substantially to fitness when larval densities are higher, because early-stage $H$. retardatus larvae sometimes experience scarcity of their typical prey. In cannibalistic oviparous amphibians, larger individuals that developed from larger eggs can more efficiently catch and consume larger prey and thus their survival maybe better than that of smaller individuals developed from smaller eggs. Populations might therefore diverge with respect to egg size in response to variation in the density of conspecific and R. pirica larvae in natural ponds, with eggs being larger when larval density is higher. I examined how variance in hatchling size correlated with the incidence of cannibalism, and whether increasing larval density in natural ponds correlated with increasing egg size. Variance in initial larval body size facilitated cannibalism, and egg size increased as larval density in the ponds increased. In ponds with high larval density, where cannibalism and large prey consumption is a critical factor in offspring fitness, the production of fewer clutches with larger eggs, and thus of fewer and larger offspring, results in greater maternal fitness. Variation among the mean egg size in populations is likely to represent a shift in optimum egg size across larval density gradients.

Key words: cannibalism - clutch size $\cdot$ egg size $\cdot$ maternal effect $\cdot$ salamander 


\section{Introduction}

Embryo mass and growth rate, especially in animals that lack parental care, are important fitness-related traits because they potentially affect juvenile survival and recruitment (Mousseau and Fox 1998). Egg size can, moreover, directly affect juvenile survival and recruitment as a result of its effect on embryo propagule mass and growth (Bernardo 1996; Sinervo and Doughty 1996; Fox et al. 1997; Einum and Fleming 1999). Larger eggs are therefore thought to confer a fitness advantage to the offspring (McGinley et al. 1987) although sometimes smaller eggs are better (Parichy and Kaplan 1995). Egg size is, in part, determined genetically (Berven 1982; Azevedo et al. 1997; Shaw and Byers 1998; Wade 1998), suggesting it can be affected by natural selection, causing subsequent variation in egg size among species or among populations within species (Shaw and Byers 1998; Wade 1998). Patterns in egg size are thought to reflect adaptive processes, especially if selection acts on offspring after hatching (Mousseau and Fox 1998).

In amphibians, variation in egg size among species or among populations within species has been commonly observed (Kaplan 1998). Both biotic (e.g. competition, predation, and resource availability) and abiotic (e.g. desiccation, temperature, and oxygen availability) environmental conditions may cause differentiation in egg size or offspring size among populations (Seymour and Bradford 1995; Kaplan 1998; Laugen et al. 2002; Thumm and Mahony 2005). Interpopulational variation in egg size is therefore likely to evolve in response to variability in aquatic environmental conditions where offspring live (Crump 1981; Berven 1982; Kaplan and Cooper 1984), although variation in egg size may also result in part from differences in environmental effects correlated with female body size (Kaplan 1998) or in the maternal environment during egg maturation. 
Larval-larval cannibalism is well documented in amphibians (Crump 1992) and, in particular, is extremely common in salamanders (Crump 1992). The larvae of the salamander, Hynobius retardatus, are carnivorous, and even though there are two larval morphs, a typical morph and a broad-headed or "cannibal" morph, both are cannibalistic (Wakahara 1997). They also sometimes eat other large prey, for example larvae of the frog, Rana pirica (Michimae and Wakahara 2002a). Because cannibalism can greatly enhance an individual's growth or rate of development (Michimae and Wakahara 2002a), it can increase the disparity in size among larvae throughout the larval period (Wakahara 1997). The presence of R. pirica larvae can also contribute to the size variance that induces cannibalism, irrespective of salamander's morph. Variation in the larval size distribution (i.e. size disparities) stimulates and facilitates the potential for cannibalism in Ambystoma tigrinum (Maret and Collins 1994), and, similarly, asynchronous hatching and variation in initial egg size may facilitate the potential for cannibalism in $A$. opacum (Kaplan 1980; Scott 1990).

The advantages to larvae and juveniles hatched from large eggs have been demonstrated for a wide range of amphibian taxa (Kaplan 1998). In cannibalistic oviparous amphibians relatively larger individuals that developed from larger eggs can more efficiently catch and consume relatively larger prey, for example conspecific larvae, and may thus have more chance of survival than individuals developed from smaller eggs. Michimae (2006) reported that carnivorous $H$. retardatus larvae live in ponds with different larval densities of conspecifics and of $R$. pirica larvae, which are detritus feeders. In natural habitats, utilization of conspecifics and $R$. pirica larvae as food may contribute to high survival and, substantially, to fitness when larval densities are higher, because $H$. retardatus larvae sometimes experience a scarcity of their typical prey (macrobenthos such as Oligochaeta and Chironomidae) during the early larval stage in ponds created by melting snow. Cannibalism accelerates metamorphosis, 
however; as a result, cannibals are much smaller at metamorphosis than larvae fed typical prey only (Michimae and Wakahara 2002a). Thus, although cannibalism can be adaptive if it increases survival during the larval life stage, there is a trade-off associated with cannibalism (accelerated development results in smaller size at metamorphosis), which can affect traits expressed later in life, resulting in negative fitness consequences and, therefore, compromising reproductive fitness (Goater 1994; Scott 1994; Altwegg and Reyer 2003).

Here I hypothesize that populations can be expected to diverge in respect of egg size in response to variation in larval densities, with larger eggs being produced when larval density is higher. To test this hypothesis, I examined:

1 whether the presence of larger larvae hatched from larger eggs promotes cannibalism, that is, whether large variation in initial larval body size triggers frequent cannibalism; and

2 whether increasing larval density in natural habitats correlates with increasing egg size.

\section{Methods}

Study populations

Larval densities in each larval habitat had previously been investigated in four ponds, located in Erimo, Konuma, Nopporo, and Tomaru, from 2002 to 2004. The mean larval density in each of four additional ponds, located in Atsuta, Kamitobetsu, Okusawa, and Toyoha, was determined in a two-year field survey conducted during the breeding seasons of 2003 and 2004 (Michimae 2006). All study sites are located in Hokkaido, Japan. The number of $H$. retardatus egg clutches in each pond and the number of eggs in 
each collected clutch were counted to estimate the conspecific larval density in each habitat. The annual density of conspecific larvae in each pond was estimated by multiplying the mean clutch size by the estimated density of clutches in the pond. The number of clutches of R. pirica eggs in the eight $H$. retardatus habitats was also counted to estimate the larval densities of $R$. pirica in each habitat. The annual density of $R$. pirica larvae in each pond was estimated by multiplying the assumed value of 800 eggs per clutch by the estimated density of clutches in the pond. The mean annual density of conspecific and $R$. pirica larvae in each pond was calculated by dividing the sum of the annual total larval densities by the number of years for which clutches were collected.

To analyze the possible effect of larval density on egg size (described below), I used the following mean larval densities (individuals $/ \mathrm{m}^{-2}$ ): Erimo (1393.5), Konuma (13.533), Nopporo (131.0), Tomaru (3799.943), Atsuta (2709.3), Kamitobetsu (423.15), Okusawa (155.62), and Toyoha (392.835). The detailed abiotic and biotic features (surface area, depth, density of clutches, and larval densities of $H$. retardatus and $R$. pirica) and geographic locations of the ponds have been described by Michimae (2006).

In 2003, fertilized clutches of $H$. retardatus were collected during the breeding season (early April to late May) from each of the eight ponds: 30 clutches each from Erimo, Konuma, Nopporo, and Tomaru, and nine clutches each from Atsuta, Kamitobetsu, Okusawa, and Toyoha.

Egg size, clutch size, and initial body size

The clutches from each population of $H$. retardatus were numbered, and the number of eggs in all clutches was counted. Five randomly selected eggs from each clutch were dejellied, and their diameters 
were measured to the nearest $0.01 \mathrm{~mm}$ under a dissecting microscope. The eggs were measured at the blastula developmental stage or earlier to minimize the effect of increasing egg size with further development. The volume of each egg was estimated by use of the formula egg volume $=(4 / 3) \times 3.14 \times r^{3}$, where $r$ is the egg radius. The mean egg size of each clutch was then calculated (sum of five egg volumes/5).

Each clutch from each population of $H$. retardatus was placed, until hatching, in a stock tank filled with $1.6 \mathrm{~L}$ dechlorinated tap water at room temperature $\left(20-21^{\circ} \mathrm{C}\right)$. When the eggs hatched, five larvae from all clutches of four populations, Erimo, Konuma, Nopporo, and Tomaru, were immediately selected and measured for total body length to the nearest $0.05 \mathrm{~mm}$ using calipers, and the mean body size of each clutch was calculated. For each clutch, the variance in initial body size were also recorded.

\section{Rearing experiment}

The induction experiment was performed with twelve clutches of $H$. retardatus from each of four ponds, Erimo, Konuma, Nopporo, and Tomaru. Each collected clutch was placed, until hatching, in a stock tank filled with 1.61 dechlorinated tap water at room temperature $\left(20^{\circ}-21^{\circ} \mathrm{C}\right)$. When the collected $H$. retardatus clutches hatched, ten selected larvae (five of which were used to measure body size, as described above) from each of the 48 were assigned to a tank $(8 \mathrm{~cm} \times 8 \mathrm{~cm} \times 8 \mathrm{~cm}$ deep $)$ filled with 0.31 dechlorinated tap water. Thus, each tank contained ten larvae from the same clutch. The experimental larvae were fed every other day by offering frozen Chironomidae from 0900 to 1200 hours. The larvae were always given enough food to eat within $3 \mathrm{~h}$, and any food remaining in their tanks was removed after the feeding period. The rearing water was also exchanged every other day during the experiments. 
All experiments were conducted in the laboratory at room temperature and with a natural light-dark schedule. Every morning during the experimental period ( 2 weeks), I recorded the tank where cannibalism had occurred because the goal of this experiment was to determine whether differences in initial larval body size promoted cannibalism.

Data analysis

To test whether the relationship between egg size and clutch size differed among populations, I performed analysis of covariance (ANCOVA) with log-transformed clutch size as covariate, log-transformed egg size as a dependent variable, and population as a factor. Next, I regressed log-transformed clutch size against log-transformed egg size of either the pooled data for the eight populations or of the separate data for each population, depending on the result from the previous ANCOVA, and calculated slopes of the resulting linear equations. Finally, I analyzed the effect of mean larval density on mean egg size in each pond by regression analysis.

Similarly, to test whether the relationship between egg size and larval body size differed among the four populations, I performed ANCOVA of larval body size, with egg size as covariate and population as a factor. I then regressed larval body size against egg size of either the pooled data for the four populations or of the separate data for each population, depending on the result from the previous ANCOVA, and calculated the slopes of the resulting linear equations.

I used a multiple logistic regression model to look for a possible association between the response variable (presence of cannibalism in each clutch) and two independent variables, variance in initial larval body size as a fixed factor and population as a random factor. The final model was determined by 
comparing the deviance (likelihood ratio test statistic) to evaluate the fit of the models, which consisted of the different combinations of and interactions among the independent variables. To determine the effects of each independent variable on the presence of cannibalism in the final model, the odds ratios were then compared among treatment groups (categorical) or for units (continuous) by the Wald $\chi^{2}$ test. Although I originally prepared 12 egg clutches from each population for the rearing experiment and the statistical analysis, one clutch from the Tomaru population was removed from the statistical analysis because the tank was lost as the result of an accident in the laboratory.

\section{Results}

ANCOVA revealed no significant interaction between population and egg size (Table 1), indicating that the relationship between egg size and clutch size did not differ among populations. The population factor was therefore pooled. The slope of the linear regression equation was significant (Fig. 1a; slope $=0.463$, $\left.r^{2}=0.440, F_{1,155}=120.756, P<0.0001\right)$, and the slope was also significantly larger than $-1\left(t_{s}=37.4\right.$, $\left.t_{0.001}[155]=3.291, P<0.001\right)$. The mean larval density of the pond to which a female belonged significantly affected the size of the eggs that she produced (Fig. $1 \mathrm{~b}$; slope $=0.002, r^{2}=0.506, F_{1,7}=$ $6.139, p=0.048$ ), with larger eggs produced in ponds with higher larval density (Fig. 1b).

No significant interaction between population and larval body size was found by ANCOVA (Table 2), indicating that the relationship between egg size and larval body size (slope) did not differ among populations. The slope (0.184) of the best-fit regression line of larval body size against egg size in the eight pooled populations was significant (Fig. $2 ; r^{2}=0.706, F_{1,118}=283.223, P<0.0001$ ).

The most parsimonious logistic regression for the presence of cannibalism was acquired by stepwise 
reduction of the number of explanatory terms from the full model and by comparison of the deviance between the models with more explanatory terms and those with fewer (Table 3). The final model included only variance in initial larval body size (Table 3). The relationship between the variance and the presence of cannibalism in the tank is plotted in Fig. 3. The probability of the presence of cannibalism in the tank increased as the variance in initial larval body size increased, as indicated by the

positive logistic regression (constant: regression coefficient $=3.338$, Wald $\chi^{2}=9.63, P=0.0019$; variance in initial body size: regression coefficient $=-6.871$, Wald $\chi^{2}=9.32, P=0.0023$; Fig. 3).

\section{Discussion}

In the gape-limited cannibalistic predator H. retardatus (Ohdachi 1994) larger body size can begin to extend an individual's cannibalistic advantage from the initial larval stages, as indicated by the positive relationship between variance and the presence of cannibalism in a tank (Fig. 3). Thus, larvae that hatch from larger eggs can grow at a proportionally faster rate than larvae that hatch from smaller eggs. To utilize other larvae more efficiently as a potential prey item, larvae must be larger at birth. Wakahara (1997) reported that size-dependent cannibalism results in an increasing disparity in size throughout the larval period and causes cannibalistic larvae to have a higher rate of successful metamorphosis. Similar examples of this phenomenon have been found in A. opacum, where the potential for size-dependent cannibalism may be greatly increased by variation in initial egg size (Kaplan 1980). These results suggest that production of larger eggs may result in higher maternal fitness, depending on specific circumstances described below, because larvae from small eggs are suitable prey items for larger larvae. An egg size-egg number trade-off explains the egg size and clutch size variances in the eight 
populations of $H$. retardatus. The negative slope of the regression line $(-0.463)$, significantly larger than -1 , indicates that clutches with a large mean egg size have a larger total egg mass than those with a small mean egg size. In this study, whether egg size depended on female size or age was not examined. It is possible that the observed differentiation in egg size among populations is, in part, attributable to nongenetic environmental effects, for example those related to female body size or age (Kaplan 1998). Genetic variation enabling selection on the basis of egg size at the population level has been shown by several studies, however (Shaw and Byers 1998; Wade 1998), suggesting that egg size is likely to evolve in response to selection imposed by the offspring's environment (Crump 1981; Berven 1982; Kaplan and Cooper 1984). In other words, for selection to act on egg size, there must be differences between fitness among offspring derived from eggs of different size.

The strategies of producing clutches of fewer large eggs or clutches of more numerous smaller eggs should result in different maternal fitness consequences in different larval-density environments. In ponds with high larval density, in which cannibalism is frequent, that is, when larval-larval cannibalism becomes a critical factor in offspring fitness, the production of clutches of fewer and larger eggs, and thus fewer and larger offspring, may result in higher maternal fitness. It is probable that females used larger amounts of resources to produce larger eggs in accordance with the increased larval density in the environment. Newly hatched $H$. retardatus larvae, which inhabit ponds created by melting snow, sometimes experience a scarcity of their typical prey during the early larval stage, which usually occurs during early spring. In the absence of typical prey it is particularly adaptive for newly hatched larvae to consume frequently encountered large prey such as conspecific or R. pirica larvae (Ohdachi 1994; Nishihara 1996; Michimae and Wakahara 2001, 2002a, b). Maternal investment strongly affects the size of eggs or offspring and the potential for cannibalism in the larval period; this results in offspring fitness 
and thus maternal fitness.

Acknowledgments I thank Dr. Masami Wakahara, two anonymous reviewers and the associate editor for their comments on the manuscript. This work was partly supported by a Grant-in-Aid for Scientific Research (No. 15009850) from the Japan Society for the Promotion of Science.

\section{References}

Altwegg R, Reyer HU (2003) Patterns of natural selection on size at metamorphosis in water frogs. Evolution 57:872-882

Azevedo RBR, French V, Partridge L (1997) Life-history consequences of egg size in Drosophila melanogaster. Am Nat 150:250-282

Bernardo J (1996) The particular maternal effect of propagule size, especially egg size: patterns, models, quality of evidence and interpretations. Am Zool 36:216-236

Berven KA (1982) The genetic basis of altitudinal variation in the wood frog Rana sylvatica. An experimental analysis of larval development. Oecologia 52:360-369

Crump ML (1981) Variation in propagule size as a function of environmental uncertainty for tree frogs. Am Nat 117:724-737

Crump ML (1992) Cannibalism in amphibians. In: Elgar MA, Crespi BJ (eds) Cannibalism: ecology and evolution among diverse taxa. Oxford, New York, pp 256-276

Einum S, Fleming JA (1999) Maternal effects of egg size in brown trout (Salmo trutta): norms of reaction to environmental quality. Proc R Soc Lond B 266:2095-2100

Fox CW, Thakar MS, Mousseau TA (1997) Egg size plasticity in a seed beetle: an adaptive maternal 
effect. Am Nat 149:149-163

Goater CP (1994) Growth and survival of postmetamorphic toads: interactions among larval history, density, and parasitism. Ecology 75:2264-2274

Kaplan RH (1980) The implications of ovum size variability for offspring fitness and clutch size within several populations of salamanders (Ambystoma). Evolution 34:51-64

Kaplan RH (1998). Maternal effects, developmental plasticity, and life history evolution. In: Mousseau TA, Fox CW (eds) Maternal effects as adaptations. Oxford, New York, pp 244-260

Kaplan RH, Cooper WS (1984) The evolution of developmental plasticity in reproductive characteristics: an application of the "adaptive coin-flipping" principle. Am Nat 123:393-410

Laugen A, Laurila A, Merila J (2002) Maternal and genetic contributions to geographical variation in Rana temporaria larval life-history traits. Biol J Linn Soc 76:61-70

Maret TJ, Collins JP (1994) Individual responses to population size structure: the role of size variation in controlling expression of a trophic polyphenism. Oecologia 100:279-285

McGinley MA, Temme DH, Geber MA (1987). Parental investment in offspring in variable environments: theoretical and empirical considerations. Am Nat 130:370-398

Michimae H (2006) Differentiated phenotypic plasticity in larvae of the cannibalistic salamander Hynobius retardatus. Behav Ecol Sociobiol 60:205-211

Michimae H, Wakahara M (2001) Factors which affect the occurrence of cannibalism and the broad-headed "cannibal" morph in larvae of the salamander Hynobius retardatus. Behav Ecol Sociobiol 50:339-345

Michimae H, Wakahara M (2002a) A tadpole-induced polyphenism in the salamander Hynobius retardatus. Evolution 56:2029-2038 
Michimae H, Wakahara M (2002b) Variation in cannibalistic polyphenism between populations in the salamander Hynobius retardatus. Zool Sci 19:703-707

Mousseau TA, Fox CW (1998) Maternal effects as adaptations. Oxford Univ. Press, New York

Nishihara A (1996) Effects of density on growth of head size in larvae of the salamander Hynobius retardatus. Copeia 1996:478-483

Ohdachi S (1994) Growth, metamorphosis, and gape-limited cannibalism and predation on tadpoles in larvae of salamanders, Hynobius retardatus. Zool Sci 11:127-131

Parichy DM, Kaplan RH (1995). Maternal investment and developmental plasticity: functional consequences for locomotor performance on hatchling frog larvae. Func Ecol 9:606-617

Scott DE (1990) Effects of larval density in Ambystoma opacum: an experiment in large-scale field enclosures: Ecology 71:296-306

Scott DE (1994) The effect of larval density on adult demographic traits in Ambystoma opacum. Ecology 75:1383-1396

Seymour RS, Bradford DF (1995) Respiration of amphibian eggs. Physiol Zool 68:1-25

Shaw RG, Byers DL (1998) Genetics of maternal and paternal effects. In: Mousseau TA, Fox CW (eds) Maternal effects as adaptations. Oxford, New York, pp 97-111

Sinervo B, Doughty P (1996) Interactive effects of offspring size and timing of reproduction on offspring reproduction: experimental, maternal, and quantitative genetic aspects. Evolution $50: 1314-1327$

Thumm K, Mahony M (2005) Is variable egg size the proximate cause of diversified bet-hedging in the hatching dynamics of the red-crowned toadlet (Pseudophryne australis) (Anura: Myobatrachidae)? Herpetologica 61:9-19 
Wade MJ (1998) The evolutionary genetics of maternal effects. In: Mousseau TA, Fox CW (eds) Maternal effects as adaptations. Oxford, New York, pp 5-21

Wakahara M (1997) Kin recognition among intact and blinded, mixed-sibling larvae of a cannibalistic salamander Hynobius retardatus. Zool Sci 14:893-899 
Figure legends

Fig. 1. a Relationship between log-transformed egg size and clutch size for individual females of Hynobius retardatus in eight populations, each of which occupies a different point along the environmental continuum in respect of the densities of conspecific and $R$. pirica larvae; $r^{2}=0.440$, $F_{1,155}=120.756, P<0.0001$. Comparison of the slope with $-1: t_{s}=37.4, t_{0.001}[155]=3.291, P<0.001$. $\mathbf{b}$ The relationship between mean egg size $( \pm \mathrm{SD})$ and larval density in the eight populations; $r^{2}=0.506$, $F_{1,7}=6.139, P=0.048$. Open circles, Erimo; open squares, Konuma; open triangles, Tomaru; open diamonds, Nopporo; filled circles, Okusawa; filled squares, Atsuta; filled triangles, Kamitobetsu; filled diamonds, Toyoha

Fig. 2. Relationship between egg size and larval body size for the four populations, Erimo, Konuma, Tomaru, and Nopporo; $r^{2}=0.706, F_{1,118}=283.223, P<0.0001$. Open circles, Erimo; open squares, Konuma; open triangles, Tomaru; open diamonds, Nopporo

Fig. 3. Relationship between variance in initial larval body size and the presence of cannibalism in a tank; constant: regression coefficient $=3.338$, Wald $\chi^{2}=9.63, P=0.0019$; variance in initial body size: regression coefficient $=6.871$, Wald $\chi^{2}=9.32, P=0.0023$. Open circles, Erimo; open squares, Konuma; open triangles, Tomaru; open diamonds, Nopporo 
Figure 1

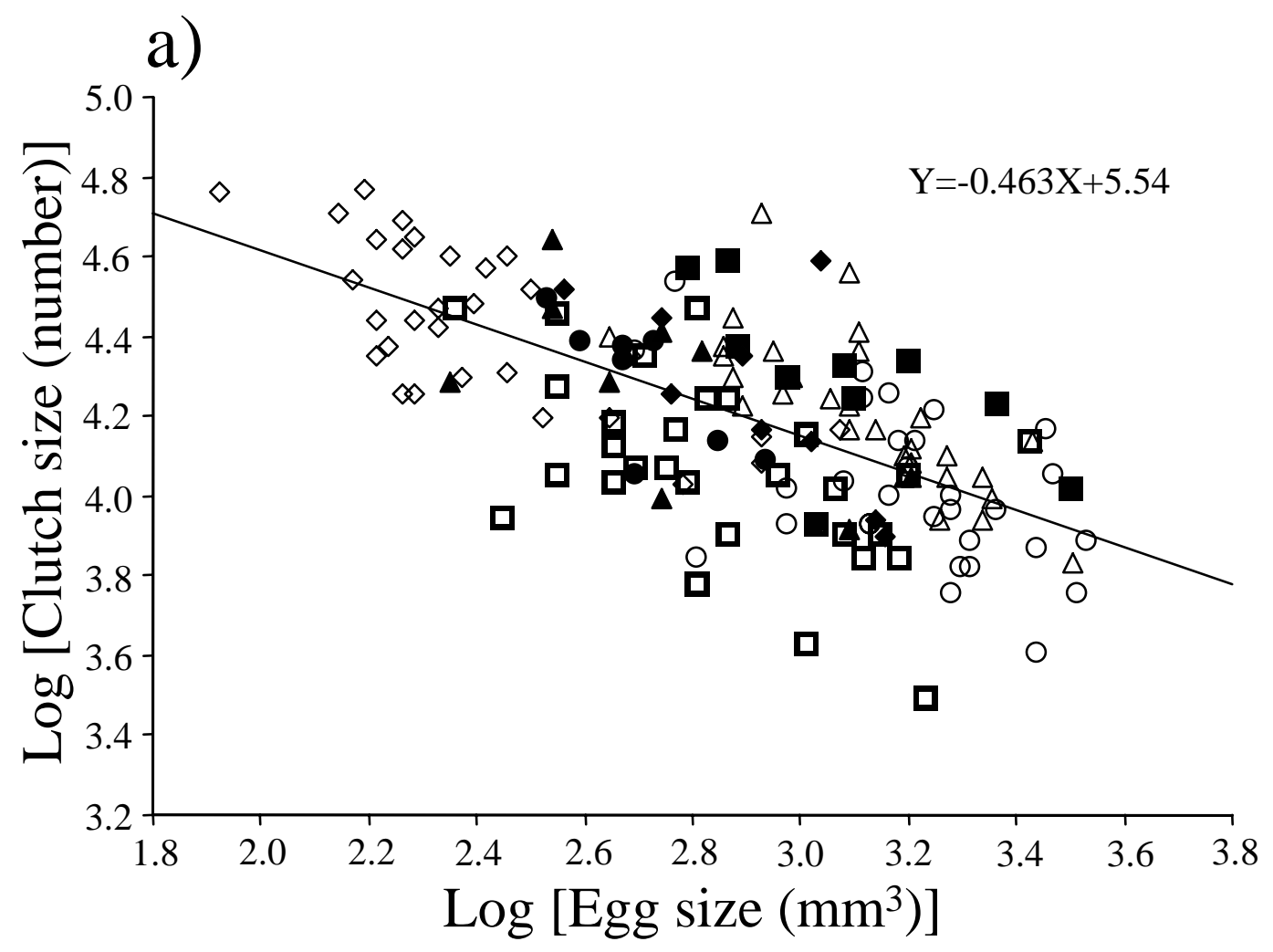

b)

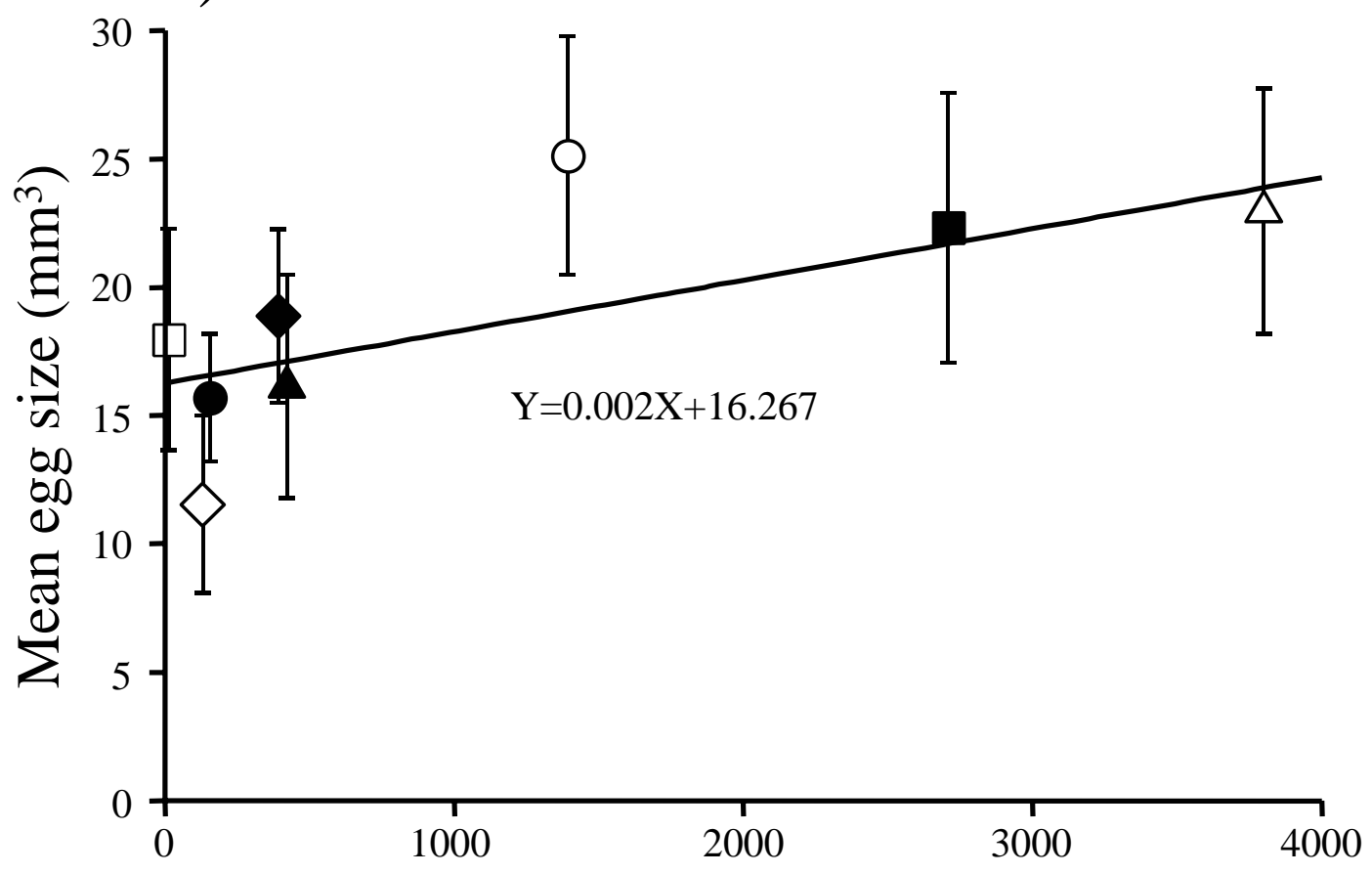

Density of $H$. retardatus and $R$. pirica

larvae (individuals $/ \mathrm{m}^{2}$ ) 
Figure 2

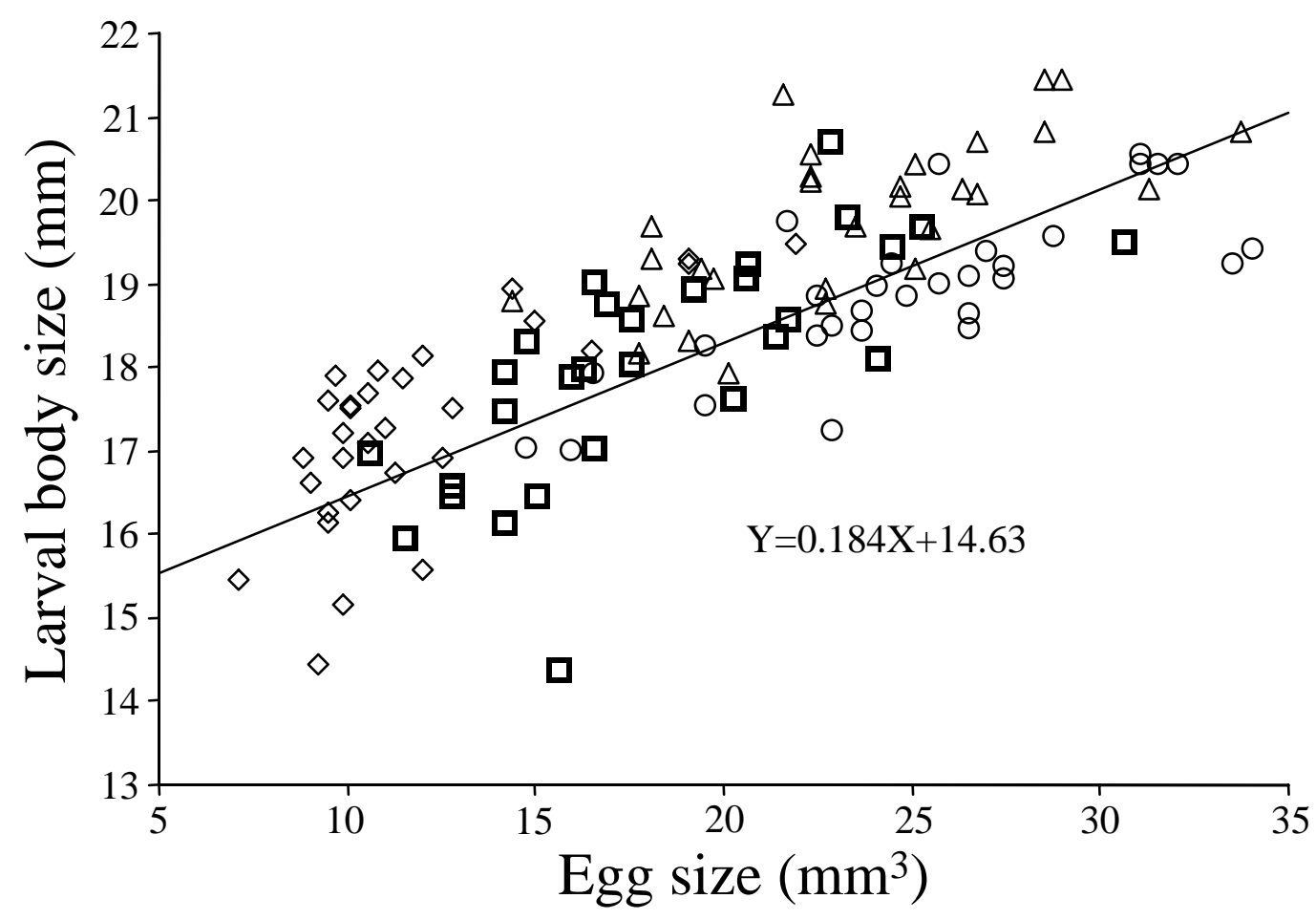


Figure 3

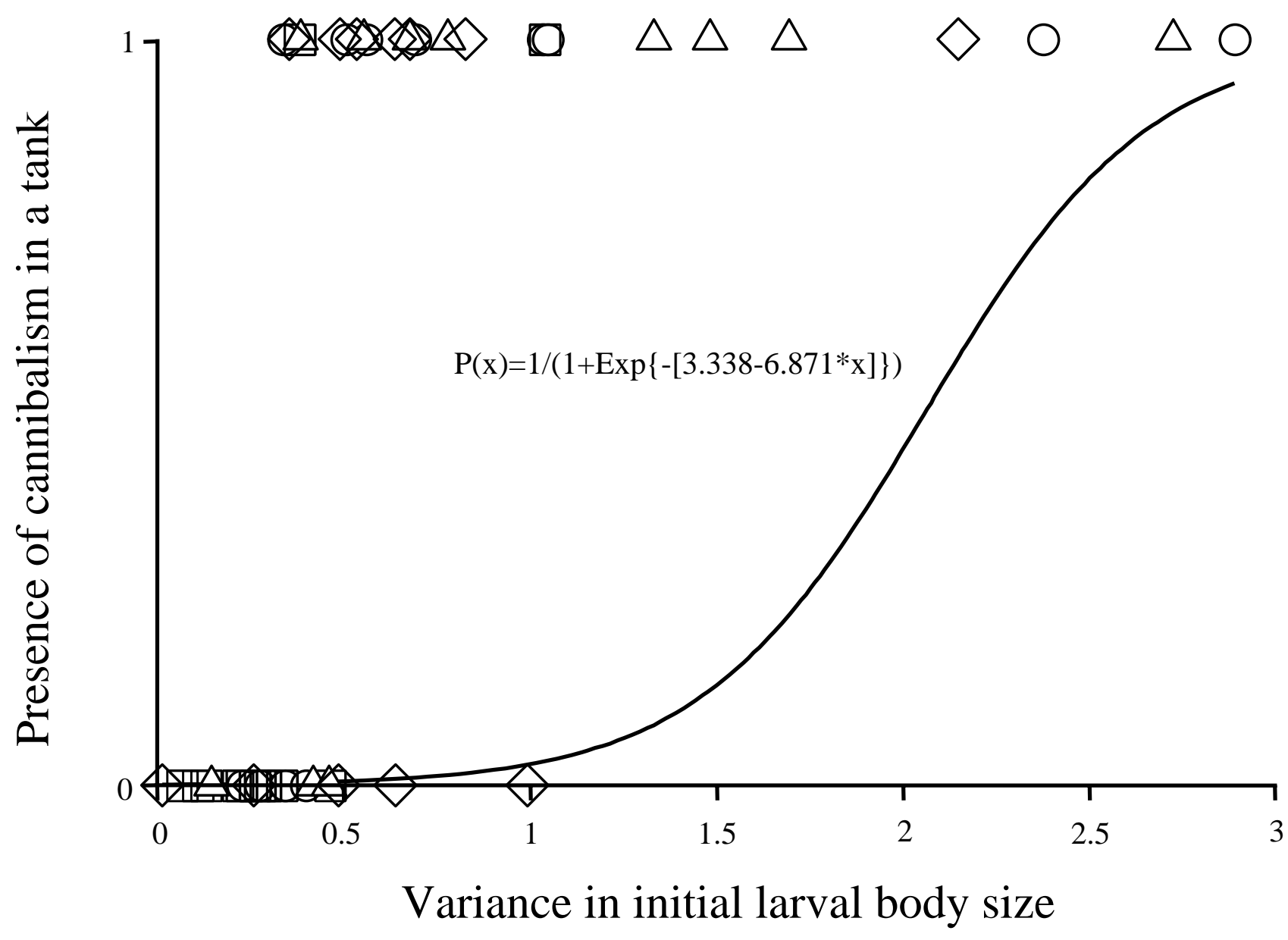


Table 1. Results from ANCOVA of the effect of population on clutch size, with egg size as covariate.

\begin{tabular}{lcccc}
\hline \hline Source & MS & d.f. & $F$ & $P$ \\
\hline Population & 0.025 & 7 & 0.947 & 0.4723 \\
Egg size & 1.980 & 1 & 75.657 & $<0.0001$ \\
Population × Egg size & 0.017 & 7 & 0.646 & 0.7175 \\
Error & 0.026 & 140 & & \\
\hline
\end{tabular}


Table 2. Results from ANCOVA of the effect of population on larval body size, with egg size as covariate.

\begin{tabular}{lcccc}
\hline \hline Source & MS & d.f. & $F$ & $P$ \\
\hline Population & 1.234 & 3 & 2.004 & 0.1175 \\
Egg size & 79.858 & 1 & 129.695 & $<0.0001$ \\
Population $\times$ Egg size & 1.257 & 3 & 0.646 & 0.1121 \\
Error & 0.616 & 112 & & \\
\hline
\end{tabular}


Table 3. Comparisons of multiple logistic regression models, which consisted of the different combinations of and interactions between the independent variable ( $V$ variance in initial body size, $\mathrm{P}$ population). Constant $+\mathrm{V}$ was selected as the final model.

\begin{tabular}{lcccccc}
\hline Model & Log-Likelihood & d.f. & variable evaluated & Deviance (d.f.) & $P$ \\
\hline Constant $+\mathrm{V}+\mathrm{P}+\mathrm{V} \times \mathrm{P}$ & 15.3935 & 7 & & & & \\
Constant $+\mathrm{V}+\mathrm{P}$ & 18.2351 & 4 & $\mathrm{~V} \times \mathrm{P}$ & 5.6832 & $(3)$ & NS \\
Constant $+\mathrm{V}$ & 19.0205 & 1 & $\mathrm{P}$ & 1.578 & $(1)$ & NS \\
Constant $+\mathrm{P}$ & 27.6407 & 3 & $\mathrm{~V}$ & $17.2404(2)$ & $<0.0005$ \\
\hline
\end{tabular}

